\title{
Produção do conhecimento sobre a temática judô em periódicos científicos da educação física
}

\author{
Production of knowledge on the subject of judo in scientific journals of physical education
}

Andreza Bandeira1 , Vinicius Machado de Oliveira², Marcos Roberto Brasil1,2

${ }^{1}$ Centro Universitário Guairacá (Uniguairacá), Guarapuava, Brasil

2 Universidade Estadual de Maringá (UEM), Maringá, Brasil

\section{HISTÓRICO DO ARTIGO \\ Recebido: 14 setembro 2021 \\ Revisado: 22 outubro 2021 \\ Aprovado: 27 outubro 2021}

\section{PALAVRAS-CHAVE:}

Artes Marciais; Conhecimento;

Revistas Eletrônicas.

\section{KEYWORDS:}

Martial Arts; Knowledge;

Electronic Journals.

\section{PUBLICADO:}

01 janeiro 2022

\begin{abstract}
RESUMO
INTRODUÇÃO: Nas últimas décadas, com a popularização do Judô no Brasil, a modalidade virou escopo de investigação científica, sobretudo no campo da Educação Física brasileira. Não obstante, em que pese a temática tenha se avolumado na literatura, esforços revisionistas sobre o tema ainda são poucos.

OBJETIVO: Verificar a produção do conhecimento sobre a temática judô em periódicos da área de Educação Física no Brasil.

MÉTODOS: Foi realizado um mapeamento sistemático em alguns dos principais periódicos da Educação Física brasileira. Para esse mapeamento, foi utilizado o descritor "JUDÔ", em um recorte temporal, do início do periódico até o ano de 2018. Todo o material coletado foi tabulado no software Microsoft Excel $2016^{\circledR}$. Além da análise descritiva, os resultados foram interpretados a luz do referencial teórico de Pierre Bourdieu. A escolha de tal referencial se deu, pois, o autor desenvolveu um modus operandi, que permite compreender as dinâmicas da estrutura do campo científico como também os tensionamentos abscondidos em torno do jogo acadêmico. RESULTADOS: Ao final do processo de seleção dos estudos, encontrou-se um total de 53 trabalhos, que constituíram parte da nossa amostra. Após as análises, os resultados apontaram as principais instituições e agentes divulgadores da temática. Destacando-se o papel da Universidade de São Paulo como principal centro de reprodução científica sobre Judô, assim como dos periódicos Revista da Educação Física da UEM e Revista Motriz como os maiores receptores de estudos relacionados a essa agenda.

CONCLUSÃO: Posteriormente as análises dos escopos de pesquisa, verificou-se que o tema tem sido mais explorado no campo dos estudos biodinâmicos do movimento humano, e que a produção na área sociocultural e pedagógica ainda é incipiente.
\end{abstract}

\section{ABSTRACT}

BACKGROUND: In the last few decades, with the popularization of Judo in Brazil, the modality became the scope of scientific investigation, especially in the Brazilian Physical Education field. However, despite the increase in studies in the literature, revisionist efforts on the subject are still few.

OBJECTIVE: This study aimed to verify the production of knowledge on the judo theme in periodicals in the Physical Education field in Brazil.

METHODS: A systematic mapping was carried out in some of the main journals of Brazilian Physical Education. For this mapping, the descriptor "UUDO" was used, in a time frame, from the beginning of the journal until the year 2018. All the collected material was tabulated in Microsoft Excel 2016® software. Besides the descriptive analysis, the results were interpreted in light of the theoretical reference of Pierre Bourdieu. The choice of such referential was because the author developed a modus operandi, which allows understanding the dynamics of the structure of the scientific field as well as the tensions hidden around the academic game.

RESULTS: At the end of the selection process, a total of 53 papers were found, which are part of our sample. After the analysis, the results show the main institutions and agents that divulge the theme. We highlight the role of the University of São Paulo as the main center of scientific reproduction on Judo, as well as the periodicals Revista da Educação Física da UEM and Revista Motriz as the largest recipients of studies related to this agenda.

CONCLUSION: After the analyses of the research scopes, it was found that the theme has been more explored in the field of biodynamic studies of human movement, and that the production in the sociocultural and pedagogical area is still incipient. 


\section{INTRODUÇÃO}

Como sabemos, o Judô é uma arte marcial fundada por Jigoro Kano em 1882 no Japão. Em linhas gerais, trata-se de uma modalidade de luta que tem como algumas das suas prerrogativas principais a defesa pessoal e o condicionamento físico (NUNES, 2020). No entanto, da mesma forma que outras práticas motrizes do gênero, o Judô tem uma forte associação com princípios morais e éticos. Essa modalidade de luta está imbuída de uma filosofia e um estilo de vida voltado ao desenvolvimento pessoal, superação, autoconhecimento, autocontrole, honra, respeito e amizade. Em outras palavras, o judô nada mais é que uma prática esportiva de condicionamento físico e lazer associada a valores culturais (GONÇALVES; SILVA, 2013). Não à toa que Kano, quando idealizou a modalidade, parece ter objetivado uma prática centrada na formação do cidadão, que contrariava o imaginário de civis da época, muito mais voltado à preparação para guerra (TRAUTMANN, 2006; NUNES, 2020).

No que se refere à prática esportiva, o Judô como modalidade olímpica esteve presente, pela primeira vez em Tóquio como apresentação no ano de 1964 (NUNES, 2020). O próprio Kano, que fazia parte do Comitê Olímpico Internacional representando o Japão, acompanhado de cerca de 200 alunos apresentaram e demonstraram a modalidade ao público. De certa forma, isso acabou influenciando para à sua difusão. Não obstante, o judô, como modalidade olímpica, só se concretizou no rol das modalidades em 1972 nas olimpíadas de Munique (NUNES; RUBIO 2012). Em sua fase inicial, existiam somente três categorias, dez anos depois, a Federação Internacional de Judô, visando tornar o esporte mais ativo, dinâmico e fácil de ser assimilado pelo público, introduziu novas regras, vigoradas nos Jogos Olímpicos de Moscou, 1980, no qual passou a ser divididas por sete categorias, estratificadas por peso e sexo (CARAZZATO; CABRITA; CASTROPIL, 1996).

Em seguimento, segundo os dados da Confederação Brasileira de Judô (CBJ), alunos de Jigoro Kano, ao chegarem no Brasil, se destacaram por levar a cabo o processo de disseminação da modalidade em diversas regiões do Brasil, resultando naquilo que Correia e Franchini (2010, p. 2) descrevem como sendo Judô: "[...] um universo amplo de manifestação antropológicas de natureza multidimensional e complexa", ou seja, uma modalidade com características cosmopolitas que fascina diferentes culturas pelo globo. Assim sendo, é notável o crescimento da modalidade em todas as regiões do país, o que se reflete, atualmente, nas participações dos atletas brasileiros em competições mundiais e olímpicas, sendo sempre destaque, tanto em desempenho, quanto ao número de medalhas e colocações.

Nessa esteira de pensamento e diante do processo de esportivização, mercantilização e espetaculizaração, fica evidente o crescimento de associações e federações representativas da modalidade, bem como sua projeção pelos múltiplos canais de mídia, cinema, revistas especializadas e mais atualmente, na segunda modernidade, com páginas e sites da internet, asseveram o fenômeno como um grande "empreendimento social" (FRANCHINI et al., 2011; CORREIA, FRANCHINI, 2010).

Em consonância a estas evidências, cabe ressaltar que o conhecimento acadêmico produzido nas diversas áreas do conhecimento não diferiu, ou seja, estamos passando por um processo, no qual, a ciência informa e orienta a vida. Isto é, com a expansão do fenômeno Judô pelo mundo todo, pesquisadores tem procurado estudar a temática sob diferentes enfoques, fornecendo conhecimento não só para o campo acadêmico, mas também para os diversos agentes sociais engajados a modalidade. Nesse contexto, dentre as áreas que tem se concentrado neste desafio, sem dúvidas, está a Educação Física, que por meio de seus pesquisadores, têm estudado esse desporto sob diferentes perspectivas.

Em linhas gerais, nas últimas décadas com a popularização da prática de Judô e sua inserção nos mais diferentes terrenos da sociedade, desde a prática recreativa até a competitiva de nível olímpico, a Educação Física se tornou uma das principais áreas a escrutinar cientificamente a modalidade. Não obstante, em que pese a expansão do Judô pelo Brasil, bem como o crescimento no número de pesquisas direcionadas à temática, ainda pouco se sabe a respeito do cenário das pesquisas em solo brasileiro. Isto é, embora os estudos tenham se avolumado na literatura, desconhece-se quem são os principais autores, quais as principais plataformas de recepção dos estudos, quais instituições mais envolvidas com o estudo do Judô, as temáticas e as áreas associadas a investigação do fenômeno. Enfim uma série de variáveis que foram pouco exploradas na literatura e que ainda permanecem desconhecidas. Dito isso, o presente empreendimento, de cariz revisionista, teve como desiderato verificar a produção do conhecimento sobre a temática Judô em periódicos da área de Educação Física no Brasil.

\section{MÉTODOS}

O estudo aqui ensejado, trata-se de uma pesquisa bibliográfica de cunho sistemático. Essa modalidade de estudo científico, que surge como alternativa para revisar rigorosamente a literatura, é baseada e elaborada na busca e coleta de materiais já publicados na literatura, tanto na forma online como na forma impressa, tendo como uma das premissas a verificação de como determinada temática tem sido estuda ou analisada no campo acadêmico-científico. Essa técnica metodológica é essencial para a realização de qualquer categoria de pesquisa, pois possibilita ao pesquisador conhecer o universo bibliográfico em torno do seu objeto de estudo, além de servir como embasamento teórico sobre o assunto tratado no empreendimento realizado (MARCONI; LAKATOS, 2003; GIL, 2019).

Com a finalidade de dimensionar quem são os principais agentes e centros divulgadores sobre a temática Judô no âmbito da Educação Física brasileira, realizamos um mapeamento sistemático de trabalhos publicados em revistas científicas nacionais. Como critérios de escolha das revistas, estabeleceu-se o seguinte: os periódicos deveriam [1] ter acesso livre a todos os números publicados, seja na forma digital, ou meio impresso; [2] serem classificados na plataforma Sucupira como pertencentes ou qualis da/em Educação Física e possuírem estrato entre A1 a B2 (20132016), por fim, [3] apresentar um espaço consolidado em seu escopo para divulgação de revisões de literatura voltada para a área biodinâmica, pedagógica e/ou sociocultural 
da Educação Física.

Dentro desse contexto, foram selecionados os seguintes periódicos científicos nacionais: Revista Brasileira de Ciência do Esporte (RBCE), Revista Brasileira de Educação Física e Esporte (RBEFE), Revista da Educação Física da UEM - Journal of Pshysical Education (JPE), Revista Licere (RL), Revista Motrivivência (RMT), Revista Motriz (RMZ), Revista Movimento (RM) e Revista Pensar a Prática (RPP).

Após a delimitação dos periódicos científicos, em uma segunda etapa da pesquisa, aprouve acessar de forma direta os sítios de cada uma das revistas selecionadas e aplicar, de forma manual ${ }^{1}$, o critério de inclusão e exclusão dos dados, por meio, do descritor proposto para esse estudo, a saber, "JUDÔ". Em um recorte temporal, desde o início do periódico até o ano de 2018, o que nos permitiu uma coleta de mais 30 anos de mapeamento sistemático.

Em seguimento, para realizar uma filtragem dos diversos dados coletados, utilizamos como critério de inclusão e exclusão, para autores e coautores dos artigos científicos, aqueles com mais de três publicações diferentes sobre a temática em tela. Nessa mesma linha de pensamento, foram incluídos as Instituições de Ensino Superior (IES) com mais de cinco trabalhos diferentes.

Com último procedimento metodológico, todo o material coletado foi tabulado no software Microsoft Excel ${ }^{\circledR}$ 2016 para a formulação do banco de dados. Nessa esteira, foram capturadas algumas informações como os autores dos estudos, os periódicos científicos que abrigam a temática, os anos de publicação dos manuscritos, as palavras-chave associadas ao objeto da pesquisa e as instituições ligadas aos autores que estudam o Judô. Por fim, no que diz respeito à apresentação dos resultados, os mesmos são apresentados em gráficos e tabelas por meio da estatística descritiva de frequência relativa e absoluta.

Além das análises estatísticas, os resultados também foram interpretados a luz do referencial teórico do sociólogo Pierre Bourdieu (BOURDIEU, 1983, 1990, 1996, 2001, $2004,2009,2013,2014)$. A escolha de tal referencial se deu por conta de que o autor em questão desenvolveu um trabalho teórico, ou modus operandi, que permite compreender não só as dinâmicas da estrutura do campo científico como também os tensionamentos abscondidos em torno do jogo acadêmico. Assim conceitos-chave da teoria bourdieusiana, como habitus, campo, capitais, distinção, dominação e, dentre outros, foram mobilizados.

\section{RESULTADOS E DISCUSSÃO}

Após feita a coleta de todos os textos disponibilizados nas plataformas de cada revista, foram encontrados um total de 10.668 obras, entre artigos originais, artigos de revisão, relatos de experiência, ensaios, resenhas, anais de eventos e entre as seções e espaços específicos de cada revista. Cabe destacar aqui, que do total averiguado (10.668), $53,9 \%(n=5.749)$ são artigos originais, 3,7\% ( $n=398)$ são artigos de revisão e $27,9 \%$ ( $n=2.978$ ) dos textos são resumos. Ensaios representam um total de 2,7\% $(n=290)$. Resenhas

A forma manual aqui se refere em verificar todos os textos de forma visual principalmente no corpo do texto, fazendo uma separação entre os textos que constam referências ao Judo como objeto. Além desse mettodo, foi utilizada a busca por meio da a palavra-chave "Judô", verificando outras formas de citação, utilização e apropriação da arte marcial. e Relatos de Experiências equivalem 1,1\% ( $n=116)$ e 1,2\% $(n=132)$, respectivamente. Os demais textos (seções específicas de cada revista) agrupados representam um total de $9,5 \%(n=1.005)$.

Na sequência, após a aplicação do descritor nos trabaIhos analisados, identificou-se a quantidade de textos associados a temática em cada uma das revistas escrutinadas. O resultado dessa análise segue socializado na tabela abaixo.

Tabela 1. Quantidade de obras coletadas e incluídas na análise Judô.

\begin{tabular}{|c|c|c|c|}
\hline Periódico científico & $\begin{array}{l}\text { Total de } \\
\text { textos } \\
\text { coletados }\end{array}$ & $\begin{array}{l}\text { Total de } \\
\text { texto } \\
\text { descritor }\end{array}$ & $\begin{array}{l}\text { Textos } \\
\text { incluídos } \\
\text { na análise }\end{array}$ \\
\hline $\begin{array}{l}\text { Revista Brasileira de Ciência do Esporte } \\
\text { (RBCE) }\end{array}$ & 2.619 & 45 & 3 \\
\hline $\begin{array}{l}\text { Revista Brasileira de Educação Física e } \\
\text { Esporte (RBEFE) }\end{array}$ & 1.012 & 55 & 9 \\
\hline Journal of Physical Education (JPE) & 921 & 78 & 11 \\
\hline Revista Licere (RL) & 696 & 28 & 2 \\
\hline Revista Motrivivência (RMT) & 787 & 39 & 8 \\
\hline Revista Motriz (RMZ) & 2.860 & 46 & 11 \\
\hline Revista Movimento (RM) & 1.000 & 53 & 5 \\
\hline Revista Pensar a Prática (RPP) & 773 & 52 & 4 \\
\hline Total & 10.668 & 396 & 53 \\
\hline
\end{tabular}

Conforme pode-se observar nos dados em tela, no total, foram encontrados 396 documentos que apresentavam o descritor "JUDÔ". Não obstante, na maioria das vezes, a palavra Judô aparecia apenas citada no texto ou nas referências bibliográficas, isto é, sem necessariamente evidenciar conexão com o objeto. À vista disso, foram excluídas um total de 10.615 produções que não possuíam relação com o objetivo ensejado nesse estudo. Assim sendo, uma vez realizado esse filtro, encontramos 53 artigos que tinham correspondência direta com o tema, ou seja, textos que direcionavam as discussões a compreensão da modalidade sob diferentes perspectivas de investigação.

Analisando a Tabela 1, pode-se observar que a RMZ e o JPE foram os periódicos científicos, que até a data de nossa busca, mais abrigaram textos sobre o tema Judô, sendo 11 artigos cada um, no período analisado. Ao contextualizar, em linhas gerais, as publicações desses dois periódicos representam quase a metade de todas as publicações $(41,5 \%)$ no campo acadêmico-científico da Educação Física no Brasil, ao menos entre os principais periódicos da área. Em seguida apresentam-se a RBEFE com 9 publicações, RMT com 8 publicações, RL com menos publicações sobre o tema no período, contando com 2 publicações.

Se analisarmos os periódicos científicos como uma forma de estrutura estruturante nos termos do sociólogo francês Pierre Bourdieu (1983; 1990; 2001; 2004; 2009; 2013; 2014), poder-se-ia dizer que a RMZ e o JPE seriam aqueles periódicos a estarem em uma posição superior (dominante) - referente à temática Judô, pelo menos em nossa amostra investigada. Nessa senda, a partir do momento que entendemos que os próprios periódicos científicos são detentores de uma legitimidade ou, em outros 
termos, autoridade, eles passam a impor algumas definições na estrutura do campo, seja por meio do poder simbólico Bourdieu $(2001,2009)$ ou pela própria divulgação do conhecimento científico que acaba por fomentar discussões que podem, inclusive, diferenciar-se, tornando seus efeitos científicos mais prolongados (BOURDIEU, 1983; $2001 ; 2004)$.

Definidos os textos investigados, em uma próxima análise das produções, verificou-se quem são os principais agentes divulgadores da temática. Nessa direção, foram elencados todos os autores e seus respectivos coautores dos 53 trabalhos. Com isso, foi possível inventariar um total de mais de 160 pesquisadores diferentes. Para efeitos de análise, sobretudo, em virtude do grande quantitativo de pesquisadores, aqueles que possuíam um número abaixo de 3 produções foram agrupados em um único grupo denominado "outros", por isso a porcentagem maior para esse grupo (85,25\%). Por consequência, a seguir são apresentados os agentes que mais possuem artigos a respeito da temática nas revistas esquadrinhadas (Tabela 02).

Tabela 2. Principais agentes divulgadores sobre a temática Judô.

\begin{tabular}{|c|c|c|c|}
\hline Autores & & $f$ & $\%$ \\
\hline Drigo, J. A. & & 4 & 2,19 \\
\hline Franchini, E. & & 7 & 3,83 \\
\hline Kiss, M. A. P. D. & & 4 & 2,19 \\
\hline Bohme, M. T. S. & & 3 & 1,64 \\
\hline Takito, Y. M. & & 4 & 2,19 \\
\hline Santos, G. S. & & 5 & 2,73 \\
\hline \multirow[t]{2}{*}{ Outros } & & 156 & 85,25 \\
\hline & Total & 162 & 100 \\
\hline
\end{tabular}

Interessante observar, que sobre os preceitos bourdieusianos, a Tabela 2 indica quais são os potenciais agentes dominantes dentro dessa estrutura do campo - sobre a temática aqui analisada - uma vez que possuem um maior quantitativo de produções socializadas nas principais revistas da área no contexto nacional (BOURDIEU, 2004). Nesse sentido, em que pese o quantitativo de pesquisas não seja o único fator para determinar o quanto o pesquisador pode ser a referência em uma área, muitas publicações de um mesmo pesquisador podem aumentar o seu alcance de divulgação, atribuindo, em tese, mais fichas acadêmicas para o agente.

Na sequência, atendendo os pressupostos do estudo, da mesma forma que os autores foram listados e posteriormente agrupados, também nos coube identificar os principais centros divulgadores da temática analisada. Nesse sentido, foi possível verificar um total de mais de 60 IES em âmbito nacional e internacional. Também para efeitos de análise e apresentação de dados, aquelas instituições com poucos artigos foram agrupadas em um único grupo. Porém, para efeito de uma melhor visualização do gráfico tal grupamento foi suprimido. Cabe ressaltar que esse tipo exclusão não compromete a análise, pelo contrário, oferece a possibilidade de uma melhor visualização dos centros divulgadores. A Figura 1 mostra esses resultados.

Ao visualizar a Figura 1, podemos constatar como prin- cipal centro divulgador da temática, a Universidade de São Paulo (USP) com 41 publicações nos periódicos analisados. Ainda nessa perspectiva, destaca-se a Universidade Federal de Santa Catarina (UFSC) com 20 produções e a Universidade de Campinas (UNICAMP) com 17 trabalhos, elencando-se também como centros divulgadores da área de Judô. Há que se ter em conta também, as Universidade Estadual Paulista (UNESP) com 16 textos, Universidade Federal do Paraná (UFPR) com 11, Universidade Estadual de Maringá (UEM) e Universidade Estadual de Londrina (UEL) com 6, e, por fim, Universidade Federal de Minas Gerais (UFMG) com 5 publicações.

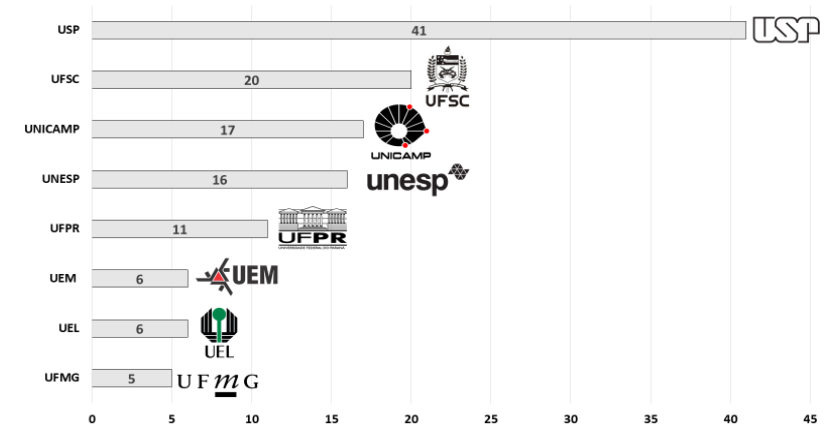

Figura 1. Principais IES divulgadoras da temática judô. Legenda: USP - Universidade de São Paulo; UFSC - Universidade Federal de Santa Catarina; UNICAMP - Universidade Estadual de Campinas; UNESP - Universidade Estadual Paulista; UFPR - Universidade Federal do Paraná; UEM - Universidade Estadual de Maringá; UEL - Universidade Estadual de Londrina; UFMG - Universidade Federal de Minas Gerais.

Nesse sentido, destacamos que os pesquisadores, bem como as IES exercem uma determinada influência no campo científico, mesmo de uma forma involuntária, ou seja, por meio do habitus científico - aquilo que Bourdieu descreve como uma teoria incorporada no agente, um conjunto de disposição, onde se destaca a linguagem corporificada e alicerçada na escrita científica, em outras palavras, um senso prático da orientação teórica tomada corpo que necessita de uma compreensão cognitiva, simbólica e de ambientação cultural (BOURDIEU, 2001; 2004). De forma geral, a posição de dominância de um polo de divulgação científica no campo acadêmico pode induzir ou delimitar a forma que com que determinado assunto é discutido (BOURDIEU, 2013).

Ao observar os principais autores e IES sobre a temática (Tabela 2 e Figura 1, respectivamente), evidenciou-se, entre outros, o papel da USP, com 41 obras e do pesquisador Emerson Franchini com mais publicações nos periódicos analisados. O autor supracitado possui doutorado em Educação Física, na área de Biodinâmica do Movimento Humano, possui ainda experiência em Educação Física e esporte, com ênfase em lutas, em especial treinamentos voltados para atletas de Judô. Em 2012, participou da comissão técnica da seleção brasileira de Judô durante os Jogos Olímpicos de Londres. Tais características, em alguma medida, explicam porque o referido autor destaca-se em relação ao número de publicações sobre a modalidade, em outros termos, parece que esse envolvimento profissional, pessoal e técnico com a temática, são os atributos que o sinalizam como o principal agente divulgador da temática. 
A importância da USP para o campo acadêmico-científico da Educação Física, fica evidente, entre tantos fatores, por ser o primeiro programa de Pós-Graduação em Educação Física no Brasil, que também é o primeiro programa da América Latina, a saber, o Programa de Pós-Graduação da Escola de Educação Física e Esporte da USP que teve seu início em março de 1977, com a criação do curso de mestrado e, em 1989, com o curso de doutorado (TANI, 2000). O referido programa possui duas áreas de concentração: "Estudos Biodinâmicos da Educação Física e Esporte" e "Estudos Socioculturais e Comportamentais da Educação Física e Esporte". Desde o ano de 2013, possui o conceito máximo (nota 7), segundo os critérios de avaliação da Coordenação de Aperfeiçoamento de Pessoal de Nível Superior (CAPES). De acordo com os dados do próprio programa, nos últimos anos, já foram formados um total de 538 mestres e mais de 170 doutores (BRASIL, 2018).

Provavelmente esse pioneirismo da USP agrega prerrogativas que permitem colocá-la em uma posição de maior notoriedade no âmbito do campo acadêmico. Desse modo, pesquisadores de diferentes áreas de formação veem na instituição uma possibilidade de maior reconhecimento científico, uma vez que agrega maiores capitais no campo acadêmico (BOURDIEU, 2001; 2009; 2014). Como consequência, há uma forte tendência que a instituição abrigue importantes pesquisadores das mais diferentes áreas do conhecimento. Mas não só isso, além de ter um corpo acadêmico notável, a instituição também dispõe de maiores recursos que, parecem, facilitar a divulgação dos trabalhos ao nível mais amplo.

Todavia, não necessariamente precisa estar conectado ao principal polo científico para se destacar no cenário, como é caso da pesquisadora Saray Giovana dos Santos que contabilizou 5 publicações nos periódicos (que representa $2,73 \%$ de todos os textos). Saray Giovana dos Santos é graduada em Educação Física pela Universidade Estadual de Maringá (UEM), possui mestrado em Ciência do Movimento Humano pela Universidade Federal de Santa Maria (UFSM), doutorado em Engenharia de Produção pela Universidade Federal de Santa Catarina (UFSC). Ao consultar o currículo da pesquisadora, verifica-se que grande parte de sua experiência profissional e científica guarda relação com o Judô, sendo, portanto, uma das referências da modalidade no que tange o campo acadêmico-científico brasileiro.

Ainda sobre os autores, destacam-se também, Monica Yuri Takito, Alexandre Janotta Drigo e Maria Augusta Peduti Dal'Molin Kiss, que possuem o mesmo número de publicações, 4 ao total (cada um representa 2,19\% de todas as obras). A autora Monica Yuri Takito é graduada em Educação Física pela USP, possui mestrado e doutorado em Saúde Pública, seu interesse principal é a promoção de saúde por meio de exercícios físicos para mulheres gestante e puérperas, suas pesquisas são com ênfase em saúde pública. Já Maria Augusta Peduti Dal'Molin Kiss possui graduação em medicina pela USP, doutorado em Fisiologia Geral, sua experiência é voltada para medicina esportiva, principalmente relacionada à avaliação do desempenho esportivo, consumo máximo de Oxigênio, entre outros temas.

E, por fim, o autor Alexandre Janotta Drigo que possui graduação em Ciências Biológicas e Educação Física, pela Universidade Estadual Paulista Júlio de Mesquita, mestra- do em Ciências da Motricidade e doutorado em Educação Física, atua principalmente na área de formação da Educação Física, com os temas: Judô, artes marciais, ética e filosofia, dentre outros temas da área.

Como pode-se observar, a maioria desses pesquisadores possui formação assente no terreno da área biodinâmica, o que influi a forma com que pesquisam a temática do Judô. Em outras palavras, ao menos entre as revistas investigadas, a modalidade de Judô tem sido explorada com mais intensidade por pesquisadores afetos à área de biodinâmica, como já foi demostrado anteriormente por Correia e Franchini (2010), ao analisar a produção do conhecimento em lutas, que constatou a proeminência da área biodinâmica do movimento quando comparado as outras áreas do conhecimento em Educação Física do Brasil.

Por consequência, estudos no prisma sociocultural ainda são mais incipientes. Nesse contexto, percebe-se que o interesse pela temática é movido principalmente pelo habitus e vivência com a modalidade esportiva em consonância com a área de formação. Isto é, entende-se que o Judô como objeto de pesquisa é produto de um conjunto de disposições e particularidades, ou melhor, uma illusio que carrega heranças históricas, depositada nos agentes acerca dos sentidos de linguagem que se materializa ou se corporifica na escrita científica (BOURDIEU, 1996, 2004, 2009). Tal por isso, os sistemas de disposições do cientista interferem no modo com o objeto é investigado (BOURDIEU, 1990, 2009; SOUZA, 2014).

Dando sequências as análises e com objetivo de analisar a cronologia dos estudos publicados, procuramos observar quando as pesquisas associadas ao Judô começam a se intensificar (Figura 2). Nesse contexto, em relação à ordem cronológica dos artigos pesquisados, optamos por buscar artigos desde o início das publicações dos periódicos até o ano de 2018. Entre os anos 1996 até 1999 encontramos 7 artigos tendo o Judô como objeto de estudo, de 2000 até 2005 foram 5 artigos publicados, nos anos de 2006 até 2010, encontramos 12 publicações, entre 2011 e 2016 foram 17 artigos publicados, sendo 4 somente no ano de 2011 e 10 em 2016. Nos anos seguintes, em 2017 e 2018, foram publicados 5 artigos em cada ano nos periódicos pesquisados.

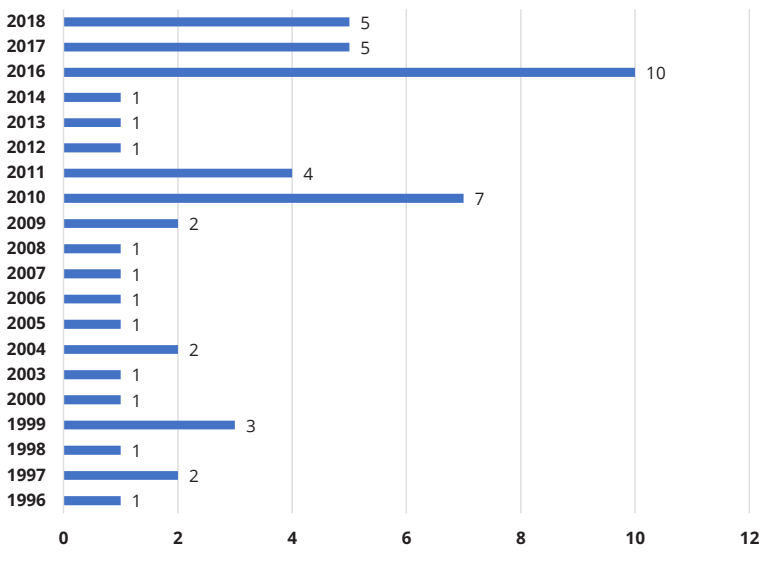

Figura 2. Ordem cronológica das publicações sobre a temática judô. 
Prosseguindo nesse debate epistemológico proposto para esse estudo, ao analisarmos as datas de publicação dos artigos que fazem parte da nossa amostra, foi possível verificar um crescimento em relação às pesquisas sobre Judô, em especial na última década. É verdade que a própria vazão de artigos como um todo no espaço editorial das revistas muito provavelmente também aumentou ao longo do tempo. Também é provável que o mesmo crescimento possa ter se feito valer em relação à circulação de outros temas de pesquisa, mas ainda assim, essa condição não inviabiliza o fato que a modalidade de Judô passou a ser mais estudada, sobretudo nos últimos anos, muito possivelmente inflamada pelos jogos olímpicos realizados no país no ano de 2016, período que conta com a maior quantidade de artigos.

Em relação à cronologia dos estudos, o primeiro texto publicado com a temática Judô, encontrado em nossa amostra, foi divulgado pelos pesquisadores Alexandre Janotta Drigo, Andrea Rodrigues de Amorim, Carlos J. Martins e Renato Molina, na ocasião, todos locados na Universidade Estadual Paulista, com o artigo intitulado: "Demanda metabólica em lutas de projeção e de solo no judô: estudo pelo lactato sanguíneo", divulgado na RMZ. Percebe-se que tal investigação está atrelada aos estudos da área fisiológica do movimento humano. Na sequência, em 1997, verifica-se a primeira publicação no JPE escrito pelos autores: Pablo Juan Greco e Jeferson Macedo Viana, intitulado: "Os princípios do treinamento técnico aplicados ao judô e a inter-relação com as fases do treinamento". Em relação a esse estudo, verifica-se que se trata de um artigo subjacente a área da pedagogia do esporte.

Em 1997, é verificado também o primeiro estudo da temática na RM de autoria de Saray Giovana dos Santos e Suely Alves Pereira, com o título: "Perfil do nível de ansiedade-traço pré-competitiva de atletas de esportes coletivos e individuais do estado do Paraná", que teve como objetivo analisar o nível de ansiedade pré-competitiva em atletas de diferentes modalidades, entre elas, o Judô. Como é possível visualizar, trata-se, evidentemente, de uma pesquisa desenvolvida no campo da Psicologia do Esporte. Além disso, interessante notar a abertura inicial da RM para estudos provenientes de fora do prisma das humanidades, uma vez que a RM, atualmente, tem dado mais espaço as pesquisas advindas da área sociocultural.

Ainda nessa perspectiva, mais aderente a área das ciências hard, chama-se atenção para o primeiro estudo publicado na RBEFE, texto que foi desenvolvido por Emerson Franchini e colaboradores, no ano de 1998, tendo como título "Características fisiológicas em testes laboratoriais e resposta da concentração de lactato sanguíneo em três lutas em judocas das classes juvenil A, júnior e sênior". Novamente, mais um texto assente no âmbito dos estudos fisiológicos, o que indica que as primeiras pesquisas relacionadas ao tema Judô se deram com mais intensidade por via da biodinâmica, o que se confirma ao inquirir as áreas de formação dos pesquisadores.

Não obstante, com a chegada dos anos 2000, pesquisas associadas mais ao campo dos estudos socioculturais da Educação Física começam também a emergir, como o caso do artigo de Orozimbo Cordeiro Júnior, intitulado de “Em busca da construção de uma proposta teórico metodológica para o ensino do judô escolar", primeiro manuscrito publicado na RPP sobre o tema, e que guarda cone- xão direta com a investigação sociocultural no contexto da Educação Física escolar. Nessa mesma direção, pode-se citar os primeiros manuscritos socializados na RMT e RL em 2005, de Patrícia Lessa, intitulado: “Mulheres, corpo e esportes em uma perspectiva feminista"; e de Romualdo Ferreira dos Santos e Cintia Lopes da Silva, "Os significados dos projetos de esporte e lazer para alunos do instituto federal do norte de minas gerais", os quais também envolveram a discussão do Judô a partir de um locus de análise mais atrelado as humanidades. Em linhas gerais, tais informações indicam que a exploração da modalidade de Judô por via da análise sociocultural, ao menos na realidade aqui perscrutada, começou apenas na virada do presente século.

Nesse contexto, essa entrada recente de pesquisadores alinhados ao campo sociocultural, sinaliza também que o Judô passa a ser investigado por novos agentes pretendentes à participação no jogo científico (BOURDIEU, 1990; 1996). Dito de outra forma, essa nova conformação sugere que no âmago da atividade científica, outros agentes advindos de outra configuração acadêmica também querem obter seu espaço em relação à temática (BOURDIEU, 1996).

Finalizando as análises propostas para esse estudo, nos aprove verificar também os principais eixos temáticos associados ao objeto estudado. Para levar a cabo essa análise, partimos com base no modelo propositado por Lazzaroti Filho et al. (2012), por meio da utilização das palavras-chave, verificar o modus operandi da veiculação em periódicos científicos do campo da Educação Física brasileira, mediante o agrupamento de categorias que contemplam as mais diversas palavras-chave utilizadas nos estudos e que, por consequência, estão relacionadas às subáreas/temas.

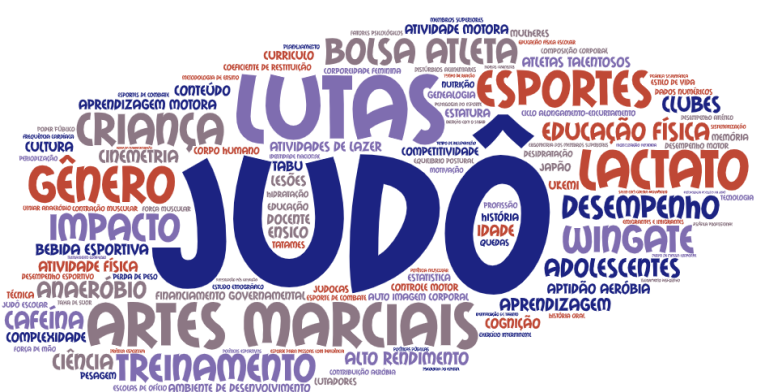

Figura 3. Nuvem de palavras-chave sobre os subtemas do judô.

Conforme pode-se observar na nuvem de palavras em questão (Figura 3), a palavra Judô aparece atrelada, em grande medida, as discussões do campo do desporto, do campo das artes marciais, do treinamento desportivo, das variáveis biodinâmicas da prática. Além disso, observa-se também palavras alinhadas ao eixo sociocultural da temática, como políticas públicas e formação profissional, em que pese com menos amplitude. Além disso, se retomado as principais palavras-chave utilizadas nos textos, pode-se identificar de que polo, a temática Judô tem sido mais investigada. Nessa senda, constata-se uma grande participação da área da biodinâmica uma vez que palavras como lactato, desempenho, wingate, treinamento e demais ter- 
mos correlatos parecem se destacar com maior ênfase na nuvem. Isso ressalta os polos de investigação da temática, bem como as áreas que ainda pouco exploraram cientificamente o objeto.

Assim sendo, em que pese verifique-se uma mobilização do objeto em diferentes subáreas da Educação Física, ainda sim, percebe-se um predomínio de determinados círculos científicos em detrimento de outros, o que pode refletir na forma com que o Judô é operacionalizado no cenário acadêmico, muito embora já se perceba um movimento de novas subáreas tentando situar também sua agenda de pesquisa na literatura. Dessa forma, não só a pluralidade de áreas investigativas é positiva para o campo, como também as disputas por capitais científicos na medida em que a discussão sobre o Judô se mantém aquecida nas mais diferentes interfaces da Educação Física.

\section{CONCLUSÃO}

Após a digressão aqui realizada, pudemos verificar que a produção de conhecimento sobre Judô pode ser considerada recente, haja vista que a análise diacrônica dos estudos revelou que a modalidade passou a ser explorada cientificamente na Educação Física apenas nos últimos 30 anos. Além disso, contatou-se que o Judô tem sido escopo maior de determinadas áreas do conhecimento, sugerindo que outros nichos da Educação Física podem contribuir de maneira fecunda na exploração do objeto, uma vez que a modalidade pode ser esquadrinhada por outros ângulos de investigação. Dessa forma, a maior produção científica sobre tema é benéfica não apenas para o campo acadêmico, mas também para agentes de fora da cidadela acadêmica, tais como treinadores e praticantes que buscam informações para aprimorar seu conhecimento sobre a modalidade, principalmente em tempos de segunda modernidade, em que os agentes sociais dos mais diferentes níveis reflexivos se mostram sedentos por acesso à informação (BECK; GIDDENS; LASH, 2012).

Por fim, em síntese, ao realizarmos uma busca sistemática da literatura sobre a modalidade Judô, em periódicos da área de Educação Física, pudemos verificar que a temática tem sido influenciada em função das trajetórias de pesquisa dos agentes e do habitus científico proveniente das dinâmicas institucionais, principalmente pela conexão com as áreas mais afetas as ciências hard. Contudo, nos últimos anos, com o processo mais intenso de ultra especialização da Educação Física, outras áreas têm adentrado no jogo acadêmico, procurando não só ingressar na discussão dos objetos como também demarcar posição no campo, o que pode ser salutar na medida em que o Judô pode ser explorado por diferentes frentes investigativas.

\section{AGRADECIMENTOS}

Os autores agradecem ao Centro Universitário Guairacá - Uniguairacá.

\section{CONFLITO DE INTERESSE}

Os autores do estudo declaram não haver conflito de interesses.

\section{FINANCIAMENTO}

Este estudo não teve apoio financeiro.

\section{REFERÊNCIAS}

BECK, U.; GIDDENS, A.; LASH, S. Modernização reflexiva: política, tradição e estética na ordem social moderna. São Paulo: Unesp, 2012.

BOURDIEU, P. Pierre Bourdieu: sociologia. São Paulo: Ática, 1983.

BOURDIEU, P. Coisas ditas. São Paulo: Brasiliense, 1990.

BOURDIEU, P. As regras da arte: Gênese e estrutura do campo literário. São Paulo: Companhia das Letras, 1996.

BOURDIEU, P. Meditações pascalianas. Rio de Janeiro: Bertrand Brasil, 2001.

BOURDIEU, P. Os usos sociais da ciência: por uma sociologia clínica do campo científico. São Paulo: Unesp, 2004.

BOURDIEU P. O poder simbólico. Rio de Janeiro: Bertrand Brasil, 2009.

BOURDIEU, P. Homo academicus. 2. ed. Florianópolis: UFSC, 2013.

BOURDIEU, P. Sobre o estado. São Paulo: Companhia das Letras, 2014.

BRASIL, M. R. Os usos da teoria sociológica de Pierre Bourdieu na área de educação física no Brasil (1977-2017). 2018. 228f. Dissertação (Mestrado em Educação Física) - Universidade Estadual de Maringá, Maringá, 2018. Disponível em: https://sucupira.capes.gov.br/sucupira/public/consultas/ coleta/trabalhoConclusao/viewTrabalhoConclusao.jsf?popup=true\&id trabalho=6390860.

CARAZZATO, J.; CABRITA, H.; CASTROPIL, W. Repercussão no aparelho locomotor da prática do judô de alto nível. Revista Brasileira de Ortopedia, São Paulo, v. 31, n. 12, p. 957-68, 1996. Disponível em: https://cdn.publisher. gn1.link/rbo.org.br/pdf/31-12/1996_dez_57.pdf.

CORDEIRO JUNIOR, O. Em busca da construção de uma proposta teóricometodológica para o ensino do judô escolar. Pensar a Prática, Goiânia, v. 3, p. 97-105, 2006. DOI: https://doi.org/10.5216/rpp.v3i0.16056. Disponível em: https://www.revistas.ufg.br/index.php/fef/article/view/16056.

CORREIA, W. R.; FRANCHINI, E. Produção acadêmica em lutas, artes marciais e esportes de combate. Motriz, Rio Claro, v. 1, n. 16, p. 1-9, 2010. Disponível em: https://www.periodicos.rc.biblioteca.unesp.br/index.php/motriz/ article/\%20view/2800/2707.

DRIGO, A. J: AMORIM, A. R.; MARTINS, C. .: MOLINA, R. Demanda metabólica em lutas de projeção e de solo no judô: estudo pela lactato sanguíneo. Motriz, Rio Claro, v. 2, n. 2, p. 80-6, 1996. Disponível em: https://www. periodicos.rc.biblioteca.unesp.br/index.php/motriz/article/view/6538.

FRANCHINI, E.; TAKITO, M. Y.; LIMA, J. R. P.; HADDAD, S.; KISS, M. A. P. D. M.; REGAZZINI, M.; BOHME, M. T. S. Physiological characteristics in laboratorial tests and blood lactate response in three fights in juvenile, junior and senior judo players. Revista Paulista de Educação Física, São Paulo, v. 12, n. 1, p. 5-15, 1998. http://dx.doi.org/10.11606/issn.2594-5904.rpef.1998.139526.

FRANCHINI, E.; Del VECCHIO, F. B.; MATSUSHIGUE, K. A.; ARTIOLI, G. G. Physiological profi les of elite judo athletes. Sports Medicine, Auckland, v. 41, n. 2, p. 147-66, 2011. DOI: http://dx.doi.org/10.2165/11538580000000000-00000.

GIL, A. C. Métodos e técnicas de pesquisa social. 7. ed. São Paulo: Atlas, 2019.

GONÇALVES, A. V. L.; SILVA, M. R. S. Artes marciais e lutas: uma análise da produção de saberes no campo discursivo da educação física brasileira. Revista Brasileira de Ciências do Esporte, São Paulo, v. 35, n. 3, p. 657-71, 2013. DOI: http://dx.doi.org/10.1590/s0101-32892013000300010.

GRECO, P. J.; VIANA, J. M. Os princípios do treinamento técnico aplicados ao judô e a inter-relação com as fases do treinamento. Revista da Educação Física, Maringá, v. 1, n. 8, p. 37-43, 1997. Disponível em: http://periodicos. uem.br/ojs/index.php/RevEducFis/article/download/3926/2697/.

LAZZAROTTI-FILHO, A.; SILVA, M. A.; NASCIMENTO, V. J.; MASCARENHAS, F. Modus operandi da produção científica da educação física: uma análise das revistas e suas veiculações. Revista da Educação Física, Maringá, v. 23, n. 1, p. 1-14. 2012. DOI: https://doi.org/10.4025/reveducfis.v23i1.12551.

LESSA, P. Mulheres, corpo e esportes em uma perspectiva feminista. Motrivivência, Florianópolis, v. 8, n. 24, p. 157-72, 2005. DOI: https://doi. org/10.5007/\%25x.

MARCONI, M. A.; LAKATOS, E. M. Fundamentos de metodologia científica, 5. ed. São Paulo: Atlas, 2003.

NUNES, A. V.: RUBIO, K. As origens do judô brasileiro: a árvore genealógica dos medalhistas olímpicos. Revista Brasileira de Educação Física e Esporte, São Paulo, v. 26, n. 4, p. 667-78, 2012. Disponível em: https://www.scielo.br/ pdf/rbefe/v26n4/v26n4a11.pdf. 
NUNES, A. V. História do judô. Disponível em: https://cbj.com.br/historia do judo. Acessado em: 30 de agosto de 2020.

SANTOS, S. G.; PEREIRA, S. A. Perfil do nível de ansiedade-traço précompetitiva de atletas de esportes coletivos e individuais do estado do Paraná. Movimento, Porto Alegre, v. 6, n. 4, p. 3-13, 1997. DOI: https://doi. org/10.22456/1982-8918.2238.

SANTOS, R. F.; SILVA, C. L. Os significados dos projetos de esporte e lazer para alunos do Instituto Federal do Norte de Minas Gerais. Licere, v. 21, n. 1, p. 267-91, 2018. DOI: http://dx.doi.org/10.35699/1981-3171.2018.1777.

SOUZA, J. O "Esporte das Multidões" no Brasil: entre o contexto de ação futebolístico e a negociação mimética dos conflitos sociais. 2014. 433f. Tese (Doutorado em Educação Física) - Universidade Federal do Paraná, Curitiba, 2014. Disponível em: http://www.pgedf.ufpr.br/downloads/ TESES/2014/TESE\%20Juliano\%20de\%20Souza.pdf.

TANI, G. Os desafios da pós-graduação em educação física. Revista Brasileira de Ciências do Esporte, SÃO Paulo, v. 22, n. 1, p. 79-90, 2000. Disponível em: http://revista.cbce.org.br/index.php/RBCE/article/view/755.
TRAUTMANN, J. V. História do judô. 2006. 32f. TCC (Graduação em Educação Física)-UniversidadeFederal do Paraná,Curitiba, 2006.Disponívelem: https:// acervodigital.ufpr.br/bitstream/handle/1884/49226/MONOGRAFIA\%20 JOAO\%2OVINICIUS\%2OTRAUTMANN.pdf?sequence=1 \&isAllowed=y.

\section{ORCID E E-MAIL DOS AUTORES}

\section{Andreza Bandeira}

(iD) http://orcid.org/0000-0002-6843-3481

Q andrezabandeira.ab@gmail.com

Vinicius Machado de Oliveira

(D) http://orcid.org/0000-0003-1789-8243

@ oliveira_vm@hotmail.com

Marcos Roberto Brasil (Autor Correspondente)

(iD https://orcid.org/0000-0001-9915-3856

@brasilmr@hotmail.com.br 